\title{
A REPRESENTAÇÃO SÓCIO-CULTURAL DO COTIDIANO RURAL NA PRODUÇÃO ARTÍSTICA DO GRUPO DA QUIXABEIRA
}

\section{Ricardo Ferreira dos Santos ${ }^{1}$}

\begin{abstract}
Resumo: Pensar as linguagens musicais da cultura regional torna-se oportuno na medida em que representam a nossa mais genuína canção popular. De uma forma simples e profundamente poética a música regional se configura como uma referência para revitalização da arte contemporânea. E o Grupo da Quixabeira constitui-se numa das mais importantes manifestações musicais do sertão e parte do recôncavo baiano, agregando várias comunidades de Feira de Santana e região, que são formadas por trabalhadores rurais que fazem do labor cotidiano uma expressão cultural rica em divertimento e poesia. Essas comunidades têm a música como uma forma de manter vivas as tradições folclóricas do povo sertanejo, evidenciando o modo de vida do nordeste interiorano. Nesse sentido, o trabalho discute a produção artística do Grupo da Quixabeira como uma forma de representação cultural na contemporaneidade.

Palavras-Chave: Grupo da Quixabeira, Cultura popular, Representação.
\end{abstract}

Abstract: Thinking about the musical languages of regional culture is opportune in so far as they embody our most genuine tradition of popular song. In a simple and profoundly poetic form regional music has become a reference for the revitalization of contemporary art. And the group "Quixabeira" has become one of the most important musical manifestations of the Bahian "sertão" and "reconcavo", combining various communities from Feira de Santana and its surroundings, being composed of rural workers who create an entertaining, richly poetic form of cultural expression on the basis of their daily labour. These communities have in their music a way of keeping alive the folk traditions of the people of the "sertão", testifying to the way of life of the northeastern interior of Brazil. This work discusses the artistic production of the group Quixabeira as a form of contemporary cultural representation.

Key Words: Quixabeira, Popular culture, Representation.

O Grupo da Quixabeira é uma expressão cultural que caracteriza a reunião de aproximadamente quinze comunidades rurais localizadas em Feira de Santana e região sisaleira. Essas comunidades, além de realizarem o trabalho no campo, desenvolvem uma estética musical calcada nos valores musicais do sertão e recôncavo baiano. Cada comunidade tem seu líder que organiza 0 repertório e as apresentações do grupo.

Esse grupo surgiu no ano de 1989, com os preparativos para a gravação de um disco. Nesse projeto, desenvolvido pela Nova - Pesquisa e Assessoria

1 Aluno do Programa de Pós-Graduação em Cultura e Sociedade - FACOM/UFBA. Ex-professor da Universidade Estadual de Feira de Santana - UEFS e da Universidade Católica de Salvador - UCSAL. 
em Educação, do Rio de Janeiro, foram lançadas as bases para a criação de uma das maiores expressões da cultura popular local, que veio a ser consolidada com a produção do vinil Da Quixabeira pro berço do rio em 1992, reunindo apenas seis comunidades (Lagoa da Camisa, Matinha dos Pretos, Subaé, Boa Vista II, Tapuio e Valente) localizadas no semi-árido baiano, que doaram suas vozes e versos para serem arranjados e arregimentados por músicos profissionais cariocas. A partir desse momento as comunidades se articularam, originando o Grupo da Quixabeira, sendo que cada uma desenvolverá seu trabalho independentemente. Com o relançamento no formato CD em 1994, essas comunidades passaram a realizar apresentações em diversos lugares. $E$ as suas canções ficaram conhecidas no universo musical, ao ponto de algumas das canções desse disco serem regravadas por artistas como: Carlinhos Brown, Caetano Veloso, Maria Bethânia, Gal Costa, Gilberto Gil, Marisa Monte e as bandas Cheiro de Amor e Harmonia do Samba.

É importante salientar que essas comunidades produzem sua música no dia-a-dia da vida no campo, ou seja, fazem do labor cotidiano uma expressão rica em poesia e musicalidade. Mais do que entretenimento, os folguedos e cantos populares são momentos onde as comunidades musical-culturais se reúnem e celebram entre si costumes e sua própria identidade.

A música tem sido ao longo do tempo uma referência na produção estética da humanidade. Praticamente todas as sociedades tiveram na música a sua forma de expressão cultural. Sociedades não-letradas usaram e usam a música para manifestarem a sua sensibilidade estética, basta citar os agrupamentos indígenas que se utilizam da música acoplada à dança para celebrarem os seus ritos, mitos e desejos. Como afirma Ernst Fischer referindo-se a função social da música primitiva:

Foi propósito da música, em seu início, o evocar emoções coletivas, o atuar como estímulo para o trabalho, para o gozo sexual e para guerra. A música era um meio de atordoar ou excitar os sentidos, um meio de prender por encantamento ou impelir à ação. Servia para pôr os homens em um estado diferente e não para refletir os fenômenos do mundo exterior (FISCHER, 1966, p. 212).

Com o surgimento das novas tecnologias ampliaram-se as possibilidades de comunicação através da música. A gravação de uma música tem uma receptividade muita mais imediata e eficiente do que a mídia impressa. E a nossa sensibilidade auditiva ficou mais aguçada com o boom da indústria fonográfica.

$\mathrm{Na}$ visão nietzschiana a música funciona como condição de possibilidade da existência humana, uma afirmação dionisíaca da vida. E a canção popular segundo o filósofo tem uma inscrição dionisíaca no sentido da vontade criadora. Para Nietzsche $(1992$, p. 48) "os movimentos orgiásticos de um povo se 
eternizam em sua música" E a poesia da canção popular, segundo o autor, tem como substrato e pressuposto as correntes dionisíacas. E Dioniso é o Deus da música, da dança, da festa, da celebração da vida, num contexto marcada pela angústia, desespero e sofrimento. $E$, na verdade, o nordestino do sertão assolado pela seca, pobreza e miséria sofre terrivelmente, mas encontra inspiração na força criativa dos versos e melodias que renova a esperança de dias melhores.

Assim, pensar as linguagens musicais da cultura regional torna-se oportuno na medida em que representam uma das mais importantes facetas da nossa canção popular. De uma forma simples e profundamente poética, a música regional se configura como uma referência para revitalização da arte contemporânea. $E$ a emergência de diversos grupos e artistas, principalmente do nordeste, mesclando os elementos da cultural regional com a música pop, como Chico Science \& Nação Zumbi, M estre Ambrósio, Cascabulho, Cordel do Fogo Encantado, Lenine, Chico César, Zeca Baleiro, só para citar alguns, reafirmam a força que a música folclórica tem para a cultura brasileira. Nas palavras impressas na contracapa do disco Da Quixabeira pro berço do rio, observa-se:

[...] mais do que registrar, documentar, algumas formas culturais em extinção massacradas pelos valores dominantes das grandes cidades e pela mídia eletrônica, este disco indica um caminho para a renovação e valorização da cultura brasileira [...].

Na verdade, o Grupo da Quixabeira constitui-se numa das mais importantes manifestações culturais do sertão baiano, agregando várias comunidades formadas por trabalhadores rurais que fazem do labor cotidiano uma expressão cultural rica em divertimento e poesia. Essas comunidades têm a música como uma forma de manter vivas as tradições folclóricas do povo sertanejo, evidenciando o modo de vida do nordeste interiorano: os seus costumes, valores, aspirações, desejos, a partir de canções que retratam o seu cotidiano, a sua relação com a natureza, consigo mesmo e com os outros. As melodias são criadas no convívio com as atividades manuais, no árduo trabalho que visa à sustentação das suas famílias.

No seu livro Cultura popular brasileira, Alceu Maynard Araújo assinala que a música e o labor estão entrelaçados no processo de criação cultural da população rurícola. As cantigas de trabalho expressam o cotidiano laborioso da mulher e do homem do campo. Diz o autor:

Embora a máquina tenha modificado em parte o uso do canto no trabalho ora substituído pela música do disco, do rádio, ainda há regiões onde o homem, só ou em grupo, pratica as cantigas de trabalho que 0 animam, ligando-o ao seu labor. 0 próprio ritmo da toada facilita muitas vezes o ritmo da operação manual. 
A música é dinomagência, um estimulante do trabalho que faz render mais (ARAÚJ0, 1973, p. 124, grifo meu).

$E$, nestes grupos sociais presentes no interior baiano, encontram-se algumas linguagens musicais que, inseridas no contexto artístico-musical do Grupo da Quixabeira, permanecem vivas através da oralidade. 0 aboio, o samba de roda, os batuques da roça, as cantigas de roda, a chula, o reisado, a bata de milho e de feijão, o boi de roça, entre outras manifestações culturais sertanejas, estão carregadas de poesia e virtuosismo. Essas tradições musicais fazem parte da memória dos trabalhadores rurais, e convivem ao lado das grandes inovações tecnológicas da música pop, numa troca rítmica e tecnicamente positiva, haja vista que as expressões regionais estão num lugar-mundo e as possibilidades de hibridização são inevitáveis.

As linguagens acima compõem o mapa cultural do Grupo da Quixabeira. Nas épocas de plantio e colheita estão todos em mutirão entoando seus versos com uma afinação e precisão rítmica de impressionar qualquer músico clássico. Nesse processo, tanto contribuem para a música contemporânea brasileira como (re)elaboram sua identidade cultural.

A gravação do disco Da Quixabeira pro berço do rio (1992) é o primeiro registro fonográfico desses senhores e senhoras (trabalhadores do campo que fazem da vida uma obra de arte) que se reuniram em comunidades e através da música expressam a sua cultura, o seu modus vivendi. Os nomes das comunidades não se referem apenas ao local que habitam, mas, sobretudo, à sua identidade musical.

As canções apresentadas por essas comunidades são em grande parte composições de domínio público e se enquadram naquilo que Alceu Maynard Araújo denomina de música folclórica, diferenciando-se da música popular (lêse música de massa), pois, fazendo referência a M ário de Andrade, essa última é vista como popularesca não só porque tem autor e intérprete, mas, sobretudo, por causa da cobertura da mídia eletrônica, vivendo "em função da moda, logo que passa, só o arquivo as guarda" (apud ARAÚJ0, 1973), seria o hit do momento. A música folclórica, segundo o autor:

[...] é conservada no escrínio da alma do povo. Foi aceita por este porque se afinou espontaneamente com o seu sentir, pensar, agir e reagir. Nasceu do povo e é para o povo e este a utiliza porque ela tem uma destinação certa (ARAÚJO, 1973, p. 118).

Ainda citando Araújo (1973, p. 118):

A música folclórica pode ou não ter autor desconhecido. Este, caso exista, acaba desaparecendo na aceitação que a coletividade dá a sua criação. Isso porque tal música foi justamente dirigida à coletividade com uma finalidade, com uma fun- 
ção. Já não interessa a autoria porque a oralidade se encarregou de difundi-la, criou-se uma aceitação coletiva.

No processo de elaboração das suas canções, as comunidades inseridas no Grupo da Quixabeira (re)constroem a sua identidade cultural superando as fronteiras entre a música regional e a música pop. Seria a fronteira entre 0 folclórico e o tecnológico, havendo uma necessidade dos artefatos eletrônicos para o registro das canções, e sua veiculação pública. Nesse sentido, a produção estética do Grupo da Quixabeira possibilita não apenas identificar o cotidiano das comunidades rurais, mas, sobretudo evidenciar uma representação cultural na contemporaneidade.

A arte trágica, enquanto concepção de música na perspectiva nietzschiana, guardadas suas devidas proporções, não chega a estar tão distante da estética musical do Grupo da Quixabeira, pois o sentido de arte - com o fundamento dionisíaco - enquanto manifestação espontânea e criativa do cotidiano é observada em ambos os contextos.

$\mathrm{Na}$ obra $\mathrm{O}$ nascimento da tragédia ou helenismo e pessimismo, Nietzsche faz uma discussão sobre a relação entre arte e conhecimento tendo a música a partir da inspiração wagneriana um lugar de destaque na ciência estética. Nessa obra, o filósofo elabora uma apaixonante apologia à arte trágica como potencializadora da existência humana tão afetada pela visão socrática-platônicacristã. No decorrer do texto, Nietzsche demonstra a oposição entre a arte apolínea - representando o belo - e a estética selvagem de Dioniso representando a força transformadora da aparência. Segundo um dos comentadores da obra do filósofo alemão, Roberto Machado:

[...] no pensamento de Nietzsche valorizar a aparência é afirmar a força; é porque a arte é uma afirmação da vida como aparência que ela cria uma superabundância de forças (MACHADO, 1984, p. 26).

É evidente a presença desse elemento - a aparência - no processo de produção musical dos trabalhadores rurais que integram o Grupo da Quixabeira, pois vivendo em circunstâncias adversas - a essência triste e medonha da vida no sertão - (re)elaboram uma herança cultural tão singular no canto, na melodia, na performance e nos versos. Ainda remetendo a Nietzsche, é importante citar uma definição da canção popular, num instante em que este autor está se aprofundando na cultura do povo grego:

A canção popular, porém, se nos apresenta, antes de mais nada, como espelho musical do mundo, como melodia primigênia, que procura agora uma aparência onírica paralela e a exprime na poesia. A melodia é portanto o que há de primeiro e mais universal, podendo por isso suportar múltiplas objetivações, em múltiplos textos. Ela é também de longe o que há de mais importante e necessário na 
apreciação ingênua do povo. De si mesma, a melodia dá à luz a poesia e volta a fazê-lo sempre de novo; é isso e nada mais que a forma estrófica da canção popular nos quer dizer: fenômeno que sempre considerei com assombro, até que finalmente achei uma explicação (NIETZSCHE, 1992, p. 48).

Nessa passagem, Nietzsche proporciona uma reflexão da cultura popular no que se refere à música. A melodia é ponto de partida para a elaboração dos versos, já que o cotidiano do camponês é um contato fatigante com a natureza, mas envolvido numa aura sinfônica de vozes que se repetem incansavelmente, como por exemplo, o aboio de roça:

[...] é uma forma de canto de trabalho, tem letra e é em dueto, além de dar-nos a impressão de um desafio por meio de versos entremeados de prolongados oi, ai, olá, cuja finalidade é excitar para maior produção de trabalho [...] (ARAÚ]0, 1973, p. 125-126).

0 aboio de roça como as demais linguagens musicais, por serem espontâneas e profundamente poéticas, possibilita as condições para o surgimento das melodias que nas vozes dissonantes aparecerão os versos dando forma à canção popular. Na definição de cultura popular de Alfredo Bosi, há uma clarividência da relação entre o universo material e o universo espiritual ou simbólico do povo sertanejo:

Cultura popular implica modos de viver: 0 alimento, o vestuário, a relação homem-mulher, a habitação, os hábitos de limpeza, as práticas de cura, as relações de parentesco, a divisão das tarefas durante a jornada e, simultaneamente, as crenças, os cantos, as danças, os jogos, a caça, a pesca, o fumo, a bebida, os provérbios, os modos de cumprimentar, as palavras tabus, os eufemismos, o modo de olhar, o modo de sentar, o modo de andar, o modo de visitar e ser visitado, as romarias, as promessas, as festas de padroeiro, o modo criar galinha e porco, os modos de plantar feijão, milho e mandioca, o conhecimento do tempo, o modo de rir e chorar, de agredir e de consolar [...] (BOSI, 1992, p. 324).

Esses elementos estão presentes no contexto dos trabalhadores rurais que formam o Grupo da Quixabeira. A vida simples e inventiva conjuga-se com o imaginário do povo sertanejo. As canções surgem da própria experiência de vida, e falam das suas relações com o meio, onde o físico e o humano estão imbricados, proporcionando uma avalanche de toadas, sons, ritmos, imagens, versos, coros, danças e performances que alegram o cotidiano de crianças, jovens, senhoras e senhores regentes de uma sinfonia sertaneja.

Analisando o processo de colheita dos trabalhadores camponeses da Inglaterra do século XVIII, Thompson chama atenção para os limites de enfoque reducionista, cuja predominância se restringe ao aspecto econômico, perdendo de vista a dimensão artístico-cultural próprio desses lugares sociais produtivos: 
E também é verdade que o bom moral dos trabalhadores era mantido graças aos bons ganhos que conseguiam nas colheitas. Mas seria um erro ver a situação das colheitas apenas em termos de resposta a estímulos puramente econômicos. É também um momento em que os velhos ritmos coletivos se entrelaçam nos novos; em que o peso do folclore e dos costumes da gente do campo são chamados a participar na satisfação psicológica das pessoas e nas funções rituais da colheita [...] (THOMPSON, 1991, p. 50-51).

Em relação à questão das culturas nacionais, observa-se, a partir de Canclini (1995, p. 144), o cruzamento das diversas culturas. Num contexto de forte influência da multimídia, é impossível manter uma pureza cultural. Segundo o autor a (re)construção das identidades culturais se apóia nas diferenças, mas inseridas em processos de hibridização intercultural na acepção do autor. Neste caso, o regional sofre interferência do global na medida em que se encontra num lugar-mundo:

Assim como noutros tempos as identidades eram objeto de encenação em museus nacionais, na segunda metade do nosso século a transnacionalização econômica, e mesmo o caráter específico das últimas tecnologias da comunicação (desde a televisão até os satélites e as redes ópticas), colocam no papel principal culturas-mundo exibidas como espetáculo multimídia (CANCLINI, 1995, p. 144).

Evidentemente que os elementos da cultura regional persistem, mesmo com os efeitos de desterritorialização da produção artística, próprios da globalização, pois o contato cultural possibilita a reconstrução das identidades regionais e nacionais. Considera-se ainda, nesta perspectiva que:

Simultaneamente à desterritorialização das artes, há fortes movimentos de reterritorialização, representados por movimentos sociais que afirmam o local e também por processos de comunicação de massa: rádios e televisões regionais, criação de micromercados de música e bens folclóricos, a "desmassificação" e a "mestiçagem" dos consumos engendrando diferenças e formas locais de enraizamento (CANCLIN, 1995, p. 146).

No contexto local, observa-se esse processo de reterritorialização da música regional com aparecimento de rádios comunitárias, programas vinculados na TVE-BA evidenciando a cultura regional e tendo como resultado a produção dos vídeo-documentários Quixabeira: da roça à indústria cultural (1998); Quixabeira: a música rural da Bahia (1999); Cantos de trabalho (2000), e a NOVA - Pesquisa e Assessoria em Educação, produzindo o disco Da Quixabeira pro berço do rio. Além da Festa da Quixabeira e da Festa da Cultura Popular que acontece na região sisaleira, reunindo diversas comunidades musicais rurais. A primeira organizada pelo M ovimento da Quixabeira e a segunda pelo M ovimento Travessuras M usicais dos Sertões.

Na concepção de Renato Ortiz a cultura popular: 
[...] é plural, e seria talvez mais adequado falarmos em culturas populares. No entanto se tomarmos como ponto de partida cada evento folclórico em particular (um reisado, uma congada), a comparação com os culto afro-brasileiros é legítima. A memória de um fato folclórico existe enquanto tradição, e se encarna no grupo social que a suporta. É através das sucessivas apresentações teatrais que ela é realimentada. Isto significa que os grupos folclóricos encenam uma peça de enredo único que constitui sua memória coletiva [...] (ORTIZ, 1986, p. 134).

As passagens dos cantos e batuques da música regional são partes integradas do folclore local, conservando-se a partir das reuniões realizadas pelas próprias comunidades. As rezas, batizados e aniversários e até mesmo as rodas de samba, que acontecem durante 0 ano, renovam e revivem essas linguagens musicais, instante em que os mais novos aproveitam para aprender os movimentos, ritmos e toadas garantindo a permanência das tradições culturais.

No caso do Grupo da Quixabeira as apresentações eventuais servem como uma forma de manter a coesão das comunidades. Mas a convivência diária nas comunidades facilita o processo de desenvolvimento artístico, já que, na visão de Carlos Brandão, "o saber popular não existe fora das pessoas, mas entre elas" (apud ORTIZ, 1986). Ainda citando Ortiz, observa-se a preocupação com a herança cultural quando ele a compara com os cultos afrobrasileiros:

A partitura musical dos grupos folclóricos distingue atores sociais, o "mestre", o "discípulo", que desempenham papéis diferenciados nas manifestações culturais. Da mesma forma que nos cultos afro-brasileiros, o problema do esquecimento se vincula às dificuldades de se manter a coesão do grupo. A morte pode desencadear um processo de desestruturação de toda uma rede de trabalho ritual, uma vez que desaparece no teatro popular. Somente após um longo aprendizado prático é que os atores podem encarnar com fidedignidade o seu papel. A memória popular (seria mais correto colocar no plural) deve portanto se transformar em vivência, pois somente desta forma fica assegurada a sua permanência através das representações teatrais (ORTIZ, 1986, p. 134-35).

É fundamental compreender a relação intrínseca dos lavradores rurais com o trabalho, isso quer dizer que o labor está incorporado na vida dos camponeses constituindo-se como um sentido da sua existência. A dureza do trabalho no campo proporciona dor, mas retira-se dele algumas alegrias que são identificadas na produção estético-musical das comunidades rurais. Fica mais evidente no momento que Ecléa Bosi faz a seguinte colocação:

Na raiz da compreensão da vida do povo está a fadiga. Não há compreensão possível do espaço e do tempo do trabalhador manual se a fadiga não estiver presente e a fome e a sede que dela nascem. $E$ as alegrias que advém desta participação no mundo através do suor e da fadiga: o sabor dos alimentos, o convívio 
da família e a vizinhança, o trabalho em grupo, as horas de descanso (BOSI, 1979, p. 27).

É justamente nessas circunstâncias que os trabalhadores rurais produzem suas alegrias manifestadas nas melodias e cantos. Um cotidiano fatigante que impulsiona a imaginação artística, pois natureza e cultura estão imbricadas. É na relação com seu contexto sócio-cultural que o povo exprime seus ritmos, sons, sentidos, enfim, a sua arte. E o Grupo da Quixabeira é a expressão possível nesse contexto, demonstrando a riqueza e diversidade da cultura brasileira.

\section{REFERÊNCIAS}

ARAÚJ0, Alceu Maynard. Cultura popular brasileira. São Paulo: Melhoramento, 1973.

BOSI, Alfredo. Dialética da colonização. São Paulo: Cia. das Letras, 1992.

BOSI, Ecléa. Problemas ligados à cultura das classes pobres. In: VALLE, Edênio; QUEIRÓZ, José J. (Org.). A cultura do povo. Coleção do Instituto de Estudos Especiais, PUCSP; n. 1. São Paulo: Cortez \& M oraes: EDUC, 1979, p. 25-34.

CANCLINI, Nestor. Consumidores e cidadãos; conflitos culturais de globalização. Rio de Janeiro: UFRJ, 1995. Capítulo: As identidades como espetáculo multimídia, p. 139-153.

FISCHER, Ernest. A necessidade da arte. Rio de Janeiro: Zahar, 1966.

M ACHADO, Roberto. Nietzsche e a verdade. Rio de Janeiro: Rocco, 1984.

NIETZSCHE, Friedrich. 0 nascimento da tragédia ou helenismo e pessimismo. Trad., notas e pósfacio de J. Guinsburg. São Paulo: Cia. das Letras, 1992.

ORTIZ, Renato. Cultura brasileira e identidade nacional. São Paulo: Brasiliense, 1986.

THOM PSON, E. T. 0 tempo, a disciplina do trabalho e o capitalismo industrial. In: SILVA, Tomaz Tadeu da. (Org.). Trabalho, educação e prática social: por uma teoria da formação humana. Porto Alegre: Artes M édicas, 1991.

CD DA QUIXABEIRA PRO BERÇO DO RIO. Produzido pela NOVA - Pesquisa e Assessoria em Educação. Rio de janeiro, 1994. 
